\title{
APRENDENDO A LIDAR COM AS DIFERENÇAS: \\ Projeto visando aumentar a inclusão social de crianças com deficiência em Moçambique
}

\author{
Luisa Reis de Freitas ${ }^{1}$
}

\begin{abstract}
Resumo
O objetivo deste trabalho é apresentar uma proposta de projeto fictíciapara a cooperação entre uma ONG (Instituição de Apoio à Criança com Deficiência) e o UNICEF Moçambique. Tendo em vista o preconceito e as dificuldades que pessoas com deficiência têm de se integrar na sociedade, o projeto buscaria promover a redução do preconceito e a inclusão social de crianças com deficiência por meio de diferentes atividades nos setores de educação e saúde nas províncias de Gaza e Inhambane. Utilizando uma metodologia de gestão de projetos, foram criados indicadores para monitoramento e avaliação das atividades, e foram identificados os riscos do projeto.
\end{abstract}

Palavras-chave:Moçambique - Projeto - Crianças - Deficência - UNICEF

\begin{abstract}
The purpose of this work is to present a fictitious project proposal for cooperation between an NGO (the Instituição de Apoio à Criança com Deficiência) and UNICEF Mozambique. In view of the prejudice and difficulties that people with disabilities have in integrating into society, the project would seek to promote the reduction of prejudice and the social inclusion of children with disabilities through different activities in the education and health sectors in the provinces of Gaza and Inhambane. Using a project management methodology, indicators were created to monitor and evaluate activities, and project risks' were identified.
\end{abstract}

Keywords:Moçambique - Project - Children - Deficiency - UNICEF

\footnotetext{
${ }^{1}$ Luisa Reis de Freitas é bacharel em Relações Internacionais pela Pontifícia Universidade Católica do Rio de Janeiro e atual mestranda em Política Ambiental, com foco em Gestão de Projetos e América Latina no InstitutD'Études Politiques-Paris. Email: 1uisarfreitas@ gmail.com.
} 


\section{Introdução}

Dentro do contexto social de Moçambique, crianças constituemo grupo mais vulnerável e que mais sofre com as mazelas da pobreza e da desigualdade social. Porém, entre as crianças, aquelas com deficiência, seja ela física, sensorial ou mental, sofrem ainda mais. Faltam educação inclusiva, cuidados médicos e de higiene apropriados e sobra preconceito por parte da sociedade. Tudo isso as coloca em uma situação de discriminação, estigma e marginalização. A ação de organizações, tanto não governamentais quanto internacionais é uma forma de complementar a ação do governo e acelerar o processo de melhorias na sociedade.

A partir de uma metodologia de elaboração de projetos sociais, este trabalho tem como objetivo apresentar uma proposta de projeto fictícia da ONG O Instituto de Apoio à Criança com Deficiência (IACD). A ideia é buscar financiamento junto ao Fundo das Nações Unidas para a Infância em Moçambique para implementar ações visando a inclusão social e a melhora das condições de vida de crianças com deficiência. A proposta foi baseada na identificação inicial do problema por meio de pesquisa e coleta de dados, e na proposição de atividades e resultados esperados de forma clara e objetiva visando a melhor compreensão por parte do financiador. Além disso, para que a proposta tenha sucesso, foi preciso garantir a competência técnica dos funcionários e métodos participativos para envolver os beneficiários ao longo do processo, iniciativas para garantir a efetividade de um projeto social (Campos et al, s.d., p. 14).

A estratégia utilizada neste projeto é a criação de um ambiente propício para a inclusão das crianças com deficiência na sociedade, combatendo os problemas identificados a partir da análise de dados iniciais. Os resultados esperados são: (1) criação de um indicador de inclusão social das crianças deficientes em Inhambane e Gaza; (2) melhoranos níveis de escolaridade das crianças, por meio da capacitação de professores, melhoria na infraestrutura das escolas e conscientização das famílias; (3) melhorados cuidados básicos de saúde e higiene, através da conscientização, acompanhamento médico e mobilização social pelo acesso à água; e, (4)

diminuição do preconceito por parte da sociedade, através da realização de encontros de diálogo, comunicação na mídia local e eventosde integração.

\section{Análise da Situação}




\section{a) A Relação entre Pobreza e Crianças com Deficiência em Moçambique}

De acordo com o Fundo das Nações Unidas para a Infância (UNICEF), a porcentagem da população que vivia abaixo da linha da pobreza caiu de 69\% em 1996/1997 para 54\% em 2002/2003 (UNICEF, 2014). Porém, dados mais recentes incluídos em outro relatório da UNICEF,afirmam que em 2008/2009, 12 milhões de pessoas ainda viviam abaixo da linha da pobreza, o que corresponde a mais da metade da população do país (UNICEF, 2011). Apesar do impressionante progresso apresentado pelo Estado na luta contra a pobreza e no desenvolvimento econômico do país, os resultados alcançados ao longo dos anos desde o fim da guerra civil, em 1992, ainda não são suficientes.

Crianças formam o grupo mais vulnerável às consequências da pobreza no curto e longo prazo. A relação entre seus efeitos negativos, como desnutrição, higiene inadequada, falta de acesso à escola e alto risco de trabalho infantil, e a sobrevivência e desenvolvimento das crianças é clara. A metodologia baseada na ideia de privações, desenvolvida por uma equipe da universidade de Bristol e utilizada pela UNICEF, é uma forma de indicar quantas crianças vivem na situação de pobreza absoluta, o que significa ter duas ou mais privações. No caso de Moçambique, esse número chegou a 48\% em 2010, situação que costuma ser mais grave nas zonas rurais. Privar as crianças de seus direitos básicos dificulta seu desenvolvimento, aumenta as chances de mortalidade e acaba prejudicando o próprio crescimento do país e da sociedade como um todo, uma vez que de acordo com o censo de 2007 as crianças representam $50 \%$ da população do país.

Entretanto, ainda dentro do universo infantil existe um grupo mais vulnerável, que sofre ainda mais com as consequências da pobreza e das privações e que tem sua situação agravada graças ao preconceito e estigma vindo da sociedade, as crianças com deficiência. Dados disponibilizados pelo UNICEF afirmam que cerca de $80 \%$ das deficiências tem causas relacionadas à pobreza e às precárias condições de vida (UNICEF, 2014b). De acordo com os dados divulgados pelo Instituto Nacional de Estatísticas (INE) de Moçambique, 14\% das crianças entre 2 e 9 anos possuem algum tipo de deficiência, sendo a surdez e a deficiência mental as mais comuns, 68,1\% das crianças com deficiência entre 0 e 17 anos não foram registradas, a maioria residente em áreas rurais, e cerca de 50,8\% das crianças deficientes entre 15 e 19 anos sofrem de 
analfabetismo. O INE afirma também que o número de crianças deficientes que frequentam as escolas é maior no início da vida escolar e vai diminuindo ao longo dos anos.

Além de todos os problemas e privações derivados da situação de pobreza, crianças com deficiência têm que lidar com uma questão muito delicada: o preconceito e o estigma por parte das comunidades, ainda muito forte dentro da cultura moçambicana. A deficiência é vista como algo negativo e fruto de diversas situações que são baseadas na cultura e religião do povo moçambicano. Acredita-se que a deficiência é fruto de um castigo divino em resposta aos pecados cometidos por algum membro da família, um problema que surgiu a partir de um feitiço feito por motivo de inveja ou vingança, ou como resultado de espíritos trazidos pela mãe da família. O que surge desse tipo de crença, em conjunto com a falta de conhecimento sobre deficiência, é o recorrente abandono de crianças com deficiência, separação entre os cônjuges e a marginalização e exclusão dessas crianças da sociedade, gerando uma situação de grave violação aos direitos dessas crianças.

Além disso, a falta de investimento em infraestrutura e capacitação nos sistemas de ensino e de saúde dificulta ainda mais a situação. Os deficientes acabam impedidos de frequentarem a escola e terem atendimento médico de qualidade porque sua situação ter locais e profissionais aptos para lidar com suas limitações e promover sua inclusão. De acordo com a Associação de Deficientes de Moçambique, apenas 2\% das crianças deficientes têm acesso à educação especial (Fórum das Organizações da Sociedade Civil para os Direitos da Criança, 2014). Com isso, acaba se instaurando um ciclo vicioso entre a pobreza e a deficiência, onde as pessoas mais pobres têm mais chance de adquirir uma deficiência devido à falta de acesso à nutrição, saúde e saneamento básico e as pessoas deficientes têm uma série de barreiras impostas no seu acesso à educação, emprego e serviços.

\section{b) O Que É a Deficiência?}

De acordo com a Primeira Política Nacional da Pessoa Portadora de Deficiência, elaborada pelo Governo de Moçambique em 1999, a pessoa portadora de deficiência é "aquela que, em razão de anomalia congênita ou adquirida, de natureza anatômica, fisiológica, sensorial ou mental, esteja em situação de desvantagem ou impossibilitada, por barreiras físicas e/ou sociais, de desenvolver normalmente uma atividade". Deficiência, por sua vez, é definida como 
"qualquer redução ou perda de capacidade normal para um ser humano resultante de um impedimento" (República de Moçambique, 1999). Seguindo a mesma ideia, a Convenção sobre Direitos da Pessoa com Deficiência (Assembleia Geral, 2006), ratificada por Moçambique em 2012, afirma que a deficiência resulta da interação entre as limitações funcionais e as barreiras atitudinais e ambientais, que podem impedir a plena e efetiva participação na sociedade. As áreas típicas da deficiência são: física, sensoriais e mentais.

Dessa forma, consideramos como criança com deficiência todo cidadão moçambicano com menos de 18 anos, não importando gênero, raça ou religião, que tenha algum tipo de deficiência, seja ela física, sensorial ou mental, que impeça ou dificulte o desenvolvimento pleno de suas capacidades e/ou sua participação na sociedade.

\section{c) A Atuação do Governo}

Ao longo dos anos, o Governo de Moçambique tem implementado uma série de projetos e estratégias para tentar melhorar a situação das crianças com deficiência, principalmente no que diz respeito à sua inclusão no sistema de ensino do país. Em 1998 o Governo criou o projeto "Escolas Inclusivas", com o apoio da Organização das Nações Unidas para a Educação, a Ciência e a Cultura (UNESCO), que tinha como objetivo combater a exclusão e levar a educação básica para todos por meio da capacitação de professores. Em 2013, o Ministério da Mulher e Ação Social, responsável pela questão dos deficientes, lançou uma campanha de comunicação com o apoio do UNICEF, que tem como objetivo promover a aceitação e inclusão dos deficientes por parte de suas famílias e da sociedade. Entretanto, apesar do Governo manter estratégias e ações para promover uma maior inclusão das crianças com deficiência, um relatório sobre os Direitos Humanoselaborado pelo Departamento de Estado Americano em 2013, afirma que a situação ainda é precária e as oportunidades na área de educação são escassas.

Além disso, a Associação dos Deficientes de Moçambique (ADEMO) denunciou no mesmo relatório que alguns programas de treinamento de professores não incluíam técnicas de como lidar com as necessidades especiais de pessoas com deficiência. A Associação também ressaltou o fato de que a infraestrutura das escolas não está preparada para receber esse tipo de alunos e está aquém dos padrões internacionais de acessibilidade. 
Uma das críticas mais recorrentes das Organizações da Sociedade Civil que atuam com o tema dos deficientes é o fato de que apesar de existirem leis, regulamentos e vontade por parte do governo de lidar com essa situação, na prática ela é bem diferente. Ricardo Moresse, Presidente do Fórum das Associações Moçambicanas dos Deficientes (FAMOD) afirmou: "As leis existem, mas há uma grande lacuna na sua implementação. A integração que tanto se fala tem que sair do discurso para a prática”. Em junhode 2012 o Governo de Moçambique declarou que realizaria um censo de pessoas portadoras de deficiência, com o objetivo de reunir informações para definir um plano educacional voltado para essa parcela da população. Porém, até a elaboração deste projeto, nenhum dado referente a essa pesquisa foi encontrado.

De acordo com o Segundo Plano Nacional de Ação para a Área de Deficiência 2012-2019 (República de Moçambique, 2012a), a área da deficiência se depara com a escassez de recursos humanos capacitados, financeiros e materiais para implementar as ações estabelecidas no plano. A ausência de parceiros e financiadores acaba prejudicando ainda mais a situação. O Plano estabeleceu um objetivo para as Organizações Não-Governamentais, que foi levado em conta pelo IACD para a elaboração deste projeto, que consiste em prestar apoio moral, técnico, material e financeiro na formulação e implementação de políticas e estratégias de ação em prol das pessoas com deficiência.

\section{d) As Áreas de Atuação Escolhidas - Educação, Saúde e Conscientização}

Dada a própria constituição do IACD, seu histórico de ações e princípios nos quais acreditamos, decidimos restringir nossa atuação às áreas de educação, saúde e conscientização da população acerca dessa situação. Sabemos que esta é apenas uma parte do problema, porém entendemos essas três áreas como a chave para um melhor desenvolvimento dessas crianças, colaborando para a criação de um futuro melhor.

Acreditamos que, no momento em que elas tiverem acesso a uma educação inclusiva e a um sistema de saúde que saiba lidar com suas necessidades, elas estarão mais próximas de alcançar um futuro melhor do que aquelas que não tiveram a mesma oportunidade. Da mesma forma como acreditamos que a conscientização da população é um fator fundamental para a redução do preconceito e estigma que existe não só com as crianças, mas com todos os deficientes. 
e) O Local de Atuação - A Província de Inhambane e Gaza

Optamos por iniciar nossas ações na província de Inhambane e Gaza. Um dos fatores que nos levaram a escolher essa província foram os dados fornecidos pelo Inquérito de Indicadores Múltiplos (MICS), disponíveis no relatório do UNICEF "Pobreza Infantil e Disparidades em Moçambique 2010", que mostram o percentual de crianças entre 2 e 9 anos com pelo menos uma deficiência relatada. Como podemos ver no gráfico abaixo, essas duas províncias são as que possuem maior porcentagem de crianças com deficiência, bem maior do que o próprio nível nacional.

Figura 1: Percentagem de crianças 2-9 anos com pelo menos uma deficiência relatada

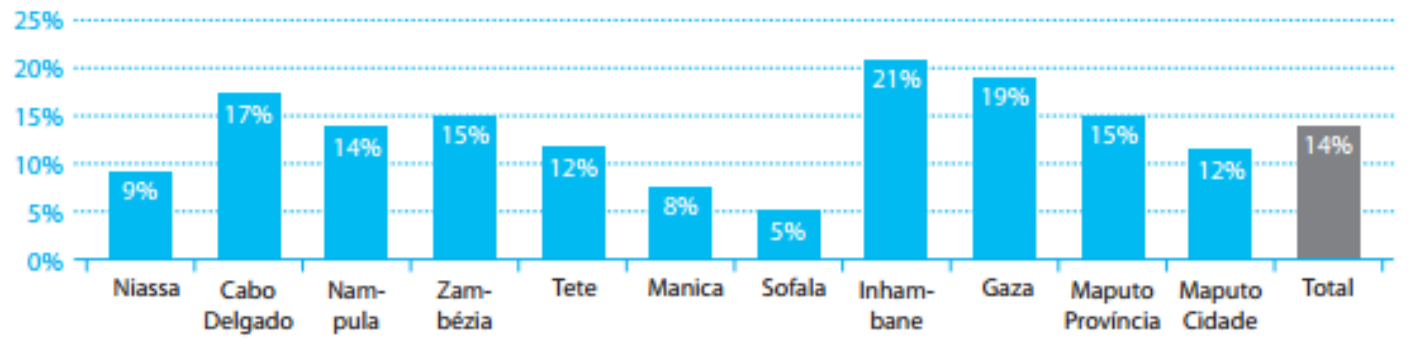

Fonte: UNICEF, 2008.

De acordo com o INE ${ }^{2}$, a taxa de analfabetismo em 2007 em Inhambane e Gaza era 41,3 e 38,5 respectivamente. Apesar de não serem as maiores taxas de analfabetismo do país, o número ainda é alto e preocupante. A tabela abaixo, disponibilizada pelo Ministério da Educação de Moçambique, mostra que em 2013 existiam 777 escolas primárias em Inhambane e 721 em Gaza, número bem abaixo de Zambézia, província que possui o maior número de escolas no país.

\footnotetext{
${ }^{2}$ Para maiores informações, ver: http://www.ine.gov.mz/pt/DataAnalysis.
} 
CADERNOS DE RELAÇÕES INTERNACIONAIS, v.11, n.2, 2017.

Figura 2: Número de Escolas, Alunos e Turmas no Ensino Primário Público, diurno, por Províncias

Valores do ADE para as escolas, ZIPs e SDEJTs, por provincias, para o ano de 2014

\begin{tabular}{|c|c|c|c|c|c|c|c|c|}
\hline \multirow{2}{*}{\multicolumn{2}{|c|}{ Código e nome da Província }} & \multicolumn{3}{|c|}{$\mathrm{EP} 1+\mathrm{EP} 2(2013)^{(\mathrm{a})}$} & \multicolumn{4}{|c|}{ Valores (Meticais) } \\
\hline & & Escolas & Alunos & Turmas & Escolas $^{(b)}$ & $\mathrm{ZIPs}^{\text {(c) }}$ & SDEJT (d) & Valor Total \\
\hline \multicolumn{2}{|c|}{ Total Pais } & 11.701 & 5.434 .529 & 108.491 & $556.957 .528,00$ & $2.117 .881,00$ & $2.515 .715,00$ & $561.591 .124,00$ \\
\hline 01 & Niassa & 1.063 & 317.161 & 6.491 & $34.836 .547,00$ & $192.403,00$ & $228.545,00$ & $35.257 .495,00$ \\
\hline 02 & Cabo Delgado & 900 & 370.889 & 7.092 & $36.953 .262,00$ & $162.900,00$ & $193.500,00$ & $37.309 .662,00$ \\
\hline 03 & Nampula & 2.029 & 976.173 & 17.490 & $96.132 .501,00$ & $367.249,00$ & $436.235,00$ & $96.935 .985,00$ \\
\hline 04 & Zambézia & 2.975 & 1.325 .190 & 24.753 & $129.362 .562,00$ & $538.475,00$ & $639.625,00$ & $130.540 .662,00$ \\
\hline 05 & Tete & 1.078 & 472.087 & 9.165 & $52.740 .217,00$ & $195.118,00$ & $231.770,00$ & $53.167 .105,00$ \\
\hline 06 & Manica & 766 & 398.885 & 9.742 & $39.860 .278,00$ & $138.646,00$ & $164.690,00$ & $40.163 .614,00$ \\
\hline 07 & Sofala & 825 & 429.872 & 8.775 & $44.211 .778,00$ & $149.325,00$ & $177.375,00$ & $44.538 .478,00$ \\
\hline 08 & Inhambane & 777 & 338.277 & 7.854 & $38.237 .161,00$ & $140.637,00$ & $167.055,00$ & $38.544 .853,00$ \\
\hline 09 & Gaza & 721 & 304.209 & 7.251 & $35.321 .505,00$ & $130.501,00$ & $155.015,00$ & $35.607 .021,00$ \\
\hline 10 & Maputo & 462 & 318.830 & 6.658 & $32.446 .423,00$ & $83.622,00$ & $99.330,00$ & $32.629 .375,00$ \\
\hline 11 & Cidade de Maputo & 105 & 182.956 & 3.220 & $16.855 .294,00$ & $19.005,00$ & $22.575,00$ & $16.896 .874,00$ \\
\hline
\end{tabular}

Fonte: INE, s.d.

Além disso, a situação da saúde também é precária nessas regiões. Os dados do INE afirmam que existiam 91 Centros de Saúde em Inhambane e 77 em Gaza. Os Centros correspondem ao nível primário do Sistema de Saúde Moçambicano, eles são os responsáveis pelos cuidados primários de saúde. Já em relação ao nível quaternário, que corresponde aos Hospitais Provinciais e Centrais, que são os responsáveis por cuidar dos doentes que não conseguem tratamento nas unidades menores anteriores, os dados mais recentes disponibilizados pelo INE datam de 2003 e afirmam que só havia um hospital em cada província.

$\mathrm{O}$ alto índice de crianças entre 2 e 9 anos com pelo menos uma deficiência relatada e os dados sobre educação e saúde evidenciam a difícil situação das crianças com deficiência em Inhambane e Gaza e justificam a delimitação geográfica para dar início a este projeto.

\section{Estratégias Propostas pelo Projeto}

\section{a) Contexto}


O objetivo principal deste projeto é gerar uma maior inclusão social de crianças com deficiência, com foco especial nas províncias de Inhambane e Gaza. As atividades propostas neste projeto foram pensadas de forma a colaborar no alcance dos objetivos de longo prazo do governo de Moçambique e demais organizações que já atuam com tema.

Em relação ao governo de Moçambique, o Plano Quinquenal do Governo de 2010 - 2014 (República de Moçambique, 2012b) afirma que o objetivo geral do governo é combater a pobreza para melhorar a qualidade de vida do povo moçambicano. Dentro desse escopo, a questão da deficiência é abordada a partir da questão da educação inclusiva, da assistência social, dos cuidados médicos e da integração com a sociedade, entre outros. Abaixo estão listados os objetivos estratégicos apresentados pelo Plano, cujos resultados estão em concordância com os objetivos deste projeto.

- Integrar crianças e jovens portadores de deficiência no ensino inclusivo;

- Melhorar o enquadramento das pessoas portadoras de deficiência em todos os subsistemas de ensino;

- Reforçar a implementação de medidas que garantam o acesso das pessoas portadoras de deficiência à reabilitação, educação, capacitação, emprego e às atividades culturais e desportivas e promover e prestar assistência;

- Integração social dos grupos em situação de vulnerabilidade, particularmente mulheres, crianças, idosos e pessoas portadoras de deficiência;

- Prestar cuidados primários de saúde aos grupos vulneráveis (crianças de 0-5 anos, mulheres grávidas ou lactantes, COVs, PVHS, pessoas idosas, mulheres e portadores de deficiência).

Além disso, o Plano Nacional de Ação para as Crianças 2013-2019 (República de Moçambique, 2012b), que identifica as áreas chave, os objetivos e as principais ações para promover o bem-estar das crianças através de uma abordagem multi-setorial, envolvendo as famílias, as comunidades e a sociedade civil, aponta como objetivo específico assegurar a proteção dos direitos das crianças em situação particular de vulnerabilidade, em situações de emergência por serem portadoras de deficiência. No que diz respeito à educação, o plano afirma 
que privilegiará a adoção de medidas para assegurar o acesso e a permanência de crianças com necessidades educativas especiais na escola. No setor da saúde, um dos objetivos do governo será fortalecer o envolvimento e a capacidade das comunidades para promoção da Saúde Materna, Neo-Natal, Infantil, Escolar e Adolescente.

Os objetivos e prioridades de ação do governo convergem com o objetivo do UNICEF no país, a priorização dos assuntos relacionados às crianças para que elas possam usufruir de seus direitos na totalidade e com qualidade. O atual Programa Nacional de Cooperação, lançado em 2012 e previsto para durar até 2015, deixa claro que o UNICEF trabalhará para assegurar que as crianças vulneráveis e as suas famílias tenham um maior acesso a serviços de saúde, nutrição e combate ao HIV. Buscará também o aumento do número de crianças que concluem o ensino primário e transitam com sucesso para o ensino secundário, com ênfase em crianças vulneráveis e meninas.

OUNICEF afirma que irá promover a formação de professores em metodologias que melhorem o nível de aprendizado, com o objetivo de incentivar a admissão de crianças com deficiência e desenvolver a aprendizagem inclusiva. Além disso, o Programa definiu que a partir de 2013 o Fundo apoiaria o Governo de Moçambique no desenvolvimento de ações de formação de professores e pessoal do Governo em matéria de práticas de cuidados e educação inclusiva para as crianças com deficiência. Haveria também o apoio para desenvolver e difundir programas de rádio e televisão que levantassem questões de estigma, proteção social e educação inclusiva.

Dessa forma, podemos afirmar que este projeto está de acordo com o interesse do Governo e do UNICEF de priorizar o bem-estar dessas crianças através de uma abordagem multisetorial na medida em que buscamos lidar com diferentes áreas e abordagens, envolvendo toda a comunidade. Capacitar os professores e adequar as escolas para diminuir a taxa de analfabetismo e evasão escolar das crianças com deficiência é uma forma de contribuir para o desenvolvimento dessa sociedade e ajudar o governo a alcançar suas metas de educação. Investir em formas de levar cuidados médicos básicos e de higiene às comunidades gerará uma mudança substancial na saúde dessas crianças e, realizar ações de conscientização a respeito da deficiência causará, no mínimo, um questionamento sobre a situação, desencadeando uma mudança no pensamento da sociedade e uma maior inclusão dessas crianças à sociedade.

Ao longo das pesquisas para a elaboração deste projeto foram identificadas algumas organizações não governamentais que tem uma participação importante no contexto de luta por 
melhorias na situação das crianças com deficiência e que podem ser apontadas como possíveis parceiros do IACD, além do Governo e do UNICEF. O Fórum das Associações Moçambicanas de Deficientes (FAMOD), composto por dezessete organizações e que busca unir esforços e utilizar uma única voz na observância, cumprimento e defesa dos direitos e interesses das pessoas com deficiência, se mostra como um dos principais possíveis parceiros do IACD neste projeto. Citamos também a Associação de Cegos e Amblíopes de Moçambique e a Associação dos Surdos de Moçambique como organizações nacionais especializadas que podem ser envolvidas em nosso trabalho.

A Handicap International também é um exemplo de organização que vem tendo um trabalho de sucesso com as crianças deficientes em Moçambique e pode fazer parte de uma rede de contatos do IACD. A ONG SavetheChildren vem trabalhando para o desenvolvimento das crianças por meio da construção de escolas, capacitação de professores e outros projetos na província de Gaza. Apesar de não lidar diretamente com crianças com deficiência, os resultados alcançados pela SavetheChildren podem servir de exemplo e inspiração para os projetos do IACD.

\section{b) Estratégias do Projeto}

O Instituto de Apoio à Criança com Deficiência é uma organização não governamental moçambicana criada em 2008 e com sede em Inhambane. Há 6 anos o IACD vem trabalhando na cidade de Inhambane com o objetivo de prestar assistência às crianças com deficiência por meio de trabalhos diretos com as escolas e instituições que abrigam essas crianças, como orfanatos e infantários. O Instituto oferece a essas crianças e suas famílias o apoio educacional, médico e psicológico necessário, além de organizar eventos para que elas tenham acesso a experiências que não teriam normalmente. Contamos com o financiamento de empresas e outras organizações para manter nosso trabalho, mas neste momento estamos buscando expandir nossa área e escopo de atuação. Por isso foi criado o projeto Aprendendo a lidar com as diferenças, com o intuito de gerar uma mudança ainda mais profunda na sociedade.

Baseados em nossa experiência com crianças deficientes, buscamos pensar em estratégias que transmitissem esse conhecimento para o restante da comunidade e contribuíssem para a mudança no pensamento e visão da sociedade. Dessa forma, podemos definir nosso projeto como 
uma forma de construção de uma sociedade mais justa por meio da prática e da conscientização da população. As atividades que compõem nossa estratégia de atuação serão:

\section{1) Pesquisa "A inclusão social de crianças com deficiência na Província de Inhambane e Gaza":}

A pesquisa com as comunidades será feita com profissionais especializados nas áreas das ciências sociais antes do início e ao final das atividades. Os pesquisadores serão responsáveis por entrevistar as comunidades ao longo da província, questionando a respeito da existência de crianças com deficiência, a situação em que vivem com suas famílias, a infraestrutura das escolas, a qualidade do ensino, o conhecimento e o acesso aos cuidados básicos de saúde e higiene, a opinião da sociedade a respeito da questão e outras perguntas pertinentes. O resultado dessa pesquisa servirá como material de análise para os pesquisadores do IACD avaliarem a real situação das crianças com deficiência nas Províncias de Inhambane e Gaza e poderem criar um indicador de inclusão social dessas crianças, avaliando seu grau de inclusão com a comunidade. A criação desse indicador será essencial tanto para a avaliação deste projeto como para futuras pesquisas e ações visando esse público.

\section{2) Curso de Capacitação de Professores:}

Visando melhorar a qualidade de ensino e evitar a evasão escolar e o analfabetismo de crianças com deficiência, ofereceremos cursos de capacitação de professores, para que eles possam aprender técnicas e formas de criar um ambiente inclusivo nas escolas. Os cursos terão duração de dois meses e meio e serão divididos em duas fases: 1 - Deficiência Física, Auditiva e Visual e 2 - Transtorno Global do Desenvolvimento, Deficiência Intelectual e Dificuldade de Aprendizado.

\section{3) Reforma da Infraestrutura das Escolas:}

As reformas nas escolas têm o objetivo de adaptar a infraestrutura e o ambiente escolar para torná-los acessíveis aos deficientes, facilitando sua locomoção e aumentando sua independência. Essas reformas serão feitas com a ajuda de voluntários cooptados por campanhas de intercâmbio e/ou trabalho voluntário, que trarão pessoas, principalmente jovens, interessados em entrar em contato com as comunidades e ajudar a melhorar suas condições. As obras serão fiscalizadas por um consultor em engenharia civil. 


\section{4) Doação de Material Didático Especial:}

A doação de material didático voltado para as necessidades especiais das crianças com deficiência também é essencial para estimulá-los a continuar seus estudos e promover sua independência no ambiente escolar. Ao ter acesso a um material adequado, as crianças deficientes serão incluídas ao terem a capacidade de acompanhar as demais durante as aulas.

\section{5) Seminários sobre a Importância de Cuidados Médicos Básicos e de Higiene:}

A falta de cuidados médicos básicos e de higiene é uma questão que pode gerar consequências sérias para as crianças com deficiência. Por terem necessidades especiais e dependerem de cuidados de terceiros, essas crianças são mais vulneráveis àdoenças transmitidas pela falta desses cuidados. Os seminários serão fundamentais para disseminar as informações sobre essa questão aqueles que convivem diariamente com as crianças com deficiência. Eles ocorrerão em encontros a cada duas semanas durante dois meses e contarão com a participação de enfermeiros, médicos e fisioterapeutas. Buscaremos parcerias com Universidades que fornecem cursos na área de saúde para que os alunos possam participar e ministrar aulas de forma voluntária como maneira de complementar seu aprendizado e colaborar com as atividades do projeto.

\section{6) Mutirões de Médicos Solidários}

Os eventos "Mutirões de Médicos Solidários” terão o objetivo de acompanhar o estado de saúde das crianças das comunidades, mas com foco especial nas crianças com deficiência. Médicos, enfermeiros e fisioterapeutas se organizarão para avaliar a saúde das crianças uma vez a cada seis meses, encaminhando os casos mais graves aos centros médicos mais próximos e auxiliando nos casos mais simples. Os participantes desses mutirões também seriam cooptados por programas de parceria com as Universidades ou a partir de trabalho voluntário. Esses profissionais teriam a supervisão de um chefe de equipe, contratado pelo IACD pelo período de vigência do projeto.

\section{7) Diálogos sobre a Deficiência}

Os Diálogos sobre a Deficiência terão um formato informal de conversas com a população, com o objetivo de se aproximar cada vez mais das pessoas, buscando criar um ambiente onde elas se sintam confortáveis para se expressar e discutir a questão do preconceito 
contra os deficientes. Serão feitos encontros mensais, sempre com a presença de um psicólogo e um sociólogo para mediar as discussões e a cada encontro haverá um especialista convidado para falar sobre sua área de estudo, como médicos, fisioterapeutas, fonoaudiólogos, entre outros. A ideia é que ocorram quatro encontros iniciaispara o ciclo básico de diálogos. Após esse período inicial serão feitos reencontros para avaliar a evolução da comunidade em relação ao preconceito e estigma em relação aos deficientes.

\section{8) Arte para Todos}

O “Arte para Todos” será um festival organizado em conjunto com a população ao longo dos cursos de capacitação e dos diálogos e marcará o fim deste ciclo inicial do projeto em cada comunidade. A ideia é criar um evento que inclua esforços de toda a comunidade, criando um senso de pertencimento e solidariedade entre os habitantes. As crianças organizarão manifestações artísticas junto com seus colegas que tiverem algum tipo de deficiência, mostrando que a inclusão é possível e que todos são capazes de se manifestar através da arte. O IACD disponibilizará todo o material necessário para o evento assim como também ajudará na sua coordenação e monitoramento, estimulando a comunidade a se envolver e colaborar.

\section{9) Estratégia de Comunicação com as Mídias Locais}

Trabalharemos junto às demais ONGs que tratam do tema para criar uma estratégia de comunicação conjunta com as mídias locais, buscando alcançar um impacto maior na sociedade moçambicana. Nosso objetivo é criar uma campanha que inclua cartazes, propagandas na mídia impressa, televisiva e nos rádios que transmitam a mensagem de que as crianças com deficiência também merecem nossa atenção e ajuda, além do fato de que suas condições não são provenientes de feitiços ou maldições. Buscaremos contato com a emissora STV, uma das principais do país, para avaliar a possibilidade de transmissão de programas que abordem o assunto e que tenham grande audiência e influência na sociedade moçambicana, como por exemplo as telenovelas brasileiras que são exibidas pelo canal. Com isso o assunto será introduzido aos poucos na vida e no dia a dia da população de Moçambique, desmistificando o problema e trazendo-o para discussão.

\section{c) O Papel do IACD e do UNICEF}


O papel do IACD neste projeto será o de organizar e monitorar a realização de todas as atividades aqui propostas. Seremos responsáveis por selecionar e preparar os profissionais para ministrar os cursos, participar dos mutirões e dos diálogos com as comunidades. Além disso, teremos a função de elaborar as campanhas de doações e captação de voluntários para realizar as obras nas escolas e trabalharemos na articulação política com as demais organizações que tratam do assunto, com o objetivo de criar a estratégia de comunicação única e para buscar maiores investimentos e respostas do governo para a melhoria nas condições de vida dos deficientes, não apenas das crianças, mas em todas as etapas da vida.

O UNICEF terá o papel de monitorar este projeto do ponto de vista financeiro e dos resultados. A avaliação por parte do Fundo é essencial, dada sua experiência com projetos de desenvolvimento em prol das crianças. Sugerimos que haja reuniões a cada seis meses com representantes do UNICEF para que sejam discutidos o andamento do projeto, seu orçamento e resultados até o momento, para que haja uma maior integração entre ambos os atores e para que possa haver feedbacks e troca de opiniões sobre o projeto, buscando evitar erros e maximizar seus resultados.

\section{d) Sustentabilidade dos Resultados}

A sustentabilidade dos resultados deste projeto estará garantida uma vez que eles foram pensados com o intuito de gerar uma transformação profunda na própria sociedade, que permanecerá ao longo do tempo, não sendo necessária a manutenção das atividades por períodos superiores aos indicados no cronograma. A maioria das atividades foram elaboradas para que a população se torne autossuficiente na sua relação com as crianças deficientes a partir do final do projeto e não tenha que depender de uma possível renovação da cooperação entre as organizações para a continuação dos resultados. Os professores capacitados e as comunidades conscientes terão papel fundamental como multiplicadores de conhecimento na manutenção desses resultados e poderão agir em prol de maiores mudanças na vida dessas crianças e da comunidade como um todo.

A única atividade que terá maiores problemas com sua sustentabilidade posterior ao fim do projeto será a da criação dos Mutirões de Médicos Solidários, que necessitarão de fundos e 
apoio para continuarem ocorrendo da forma planejada. Porém, esperamos estabelecer uma parceria com o governo ou outras organizações financiadoras para que essa ideia seja implementada de forma efetiva e não deixe de existir após os três anos do projeto.

Resultados Esperados

Os resultados previstos por este projeto, a criação de um indicador de inclusão social das crianças com deficiência, a melhora no nível de escolaridade, a melhora substantiva nos níveis de cuidados de saúde básicos e de higiene e a diminuição do preconceito e estigma da sociedade em relação a essas crianças estão diretamente relacionados e são essenciais para alcançar o objetivo principal deste projeto, que é a maior inclusão social das crianças com deficiência nas Províncias de Gaza e Inhambane. Nossa esperança é que aqueles que sofrem com a deficiência, seja ela motora, mental ou sensorial, deixem de ser vistos como um fardo, como algo que deve ser escondido e passem a se tornar parte integrante da sociedade, criando um país que aceita a diferença e sabe lidar com as diversidades de seus cidadãos.

O primeiro resultado, a criação de um indicador de inclusão social das crianças com deficiência, foi pensado para suprir uma necessidade metodológica dos estudos e projetos para lidar com a situação das crianças com deficiência. Esperamos que esse indicador seja um resultado que ajude não só o IACD a planejar e verificar progresso do Aprendendo a lidar com as diferenças, mas que também seja útil para o governo e demais organizações que desejem estabelecer políticas públicas, projetos e ações voltados para essa parcela da população. Também esperamos que este seja apenas o início de um projeto que incluirá todo o país e ajudará ainda mais crianças deficientes.

Em relação ao segundo resultado, melhorar os níveis de escolaridade das crianças com deficiência, as atividades propostas, capacitar professores, melhorar a infraestrutura das escolas e fornecer o material adequado para as necessidades especiais dessas crianças são passos fundamentais para alcançá-lo. É de conhecimento de todos que a chave para o desenvolvimento pessoal do indivíduo e da comunidade é a educação. A partir de uma educação inclusiva e de qualidade é possível abrir diversas portas para seu crescimento, buscando interromper o ciclo entre pobreza e deficiência. E é por meio de uma educação inclusiva que as crianças deficientes serão capazes de se desenvolver e se integrar à comunidade de forma plena.

Ao final dos três anos de projeto no mínimo 230 professores serão capacitados, ou seja, contamos com um número mínimo de 10 professores interessados nos cursos por distrito. 
Acreditamos que este número poderá chegar a 500, com uma média de 20 pessoas matriculadas por curso, que totalizará uma média de 250 professores em cada província. Entretanto, esse número poderá ser maior a partir da pesquisa inicial, que nos ajudará a mapear o interesse dos professores pelos cursos oferecidos e poderemos ter uma ideia mais concreta a respeito dos resultados. No que diz respeito às escolas, esperamos que os ciclos de reforma em cada distrito sejam capazes de melhorar a infraestrutura de, no mínimo, duas escolas a cada ciclo de reformas, ou seja, a cada dois meses e meio, podendo chegar à três ou quatro escolas dependendo das reformas necessárias e do número de voluntários. Ao final dos três anos esperamos ter criado ambientes acessíveis às crianças com deficiência em 50 escolas nas duas províncias.

Como terceiro resultado esperamos contribuir para a melhoria na saúde das crianças com deficiência a partir da disseminação de informações sobre os cuidados médicos básicos e de higiene especializados para as crianças deficientes. Como dito anteriormente, as pessoas que possuem algum tipo de deficiência acabam sendo mais vulneráveis e estão mais propensas a terem algum problema de saúde gerado por falta de cuidados básicos e de higiene, por isso devem ser alvo de uma atenção especial, principalmente aquelas que ainda dependem de suas famílias para isso. Criar seminários para ensinar essas famílias a cuidarem melhor de suas crianças gerará uma mudança significativa nos níveis de saúde das crianças deficientes. A criação dos Mutirões da Solidariedade também será importante para acompanhar o estado de saúde dessas crianças, uma vez que muitas vezes elas não têm acesso aos serviços de saúde oferecidos pelo governo.

Esperamos alcançar ao final do projeto um público de mais de mil pessoas ao longo de todos os distritos, baseados em uma média esperada de 45 pessoas em cada seminário. Por meio dos mutirões, esperamos ter como pacientes uma média de 30 pessoas por distrito, totalizando quase 700 pessoas tendo a saúde monitorada ao longo dos três anos nas duas províncias.

Além de cuidar da educação e da saúde dessas crianças, é necessário cuidar da forma como elas serão recebidas pela sociedade e por suas próprias famílias. Para que a inclusão dos deficientes seja completa, é preciso que a ideia de que a deficiência é fruto de feitiços e maldições seja erradicada. Por isso, a realização de encontros da comunidade que convive com essas crianças com profissionais especializados, como antropólogos, sociólogos, entre outros é essencial, afinal, o conhecimento é a principal arma contra o preconceito. A partir do momento que a sociedade moçambicana acreditar que a deficiência é uma condição genética, de doenças ou 
acidentes e não por razões sobrenaturais, eles passarão a ver os deficientes com outros olhos e deixarão de optar pela sua exclusão do convívio social.

Em cada encontro realizado nos distritos, esperamos uma média de presença de 100 pessoas já que o público alvo consiste em toda a comunidade. Dessa forma, ao final do projeto teremos alcançado 2.300 pessoas por meio dos diálogos com a comunidade, número que pode crescer ainda mais se contabilizado o fato de que cada pessoa que participar poderá servir como multiplicador do conhecimento e passará a informação adiante para pessoas que não participaram dos diálogos.

Portanto, é possível perceber que este projeto aborda os três pontos principais que mais dificultam o acesso da criança com deficiência ao desenvolvimento pleno e integração com a sociedade. Garantir o crescimento de uma criança com deficiência significa garantir o crescimento de uma sociedade como um todo, tanto em termos econômicos, a partir da criação de mão de obra, como em termos sociais, com a aceitação da diversidade e fim do preconceito. $\mathrm{O}$ que este projeto busca é que a comunidade moçambicana passe a enxergar a deficiência em sua totalidade. Queremos criar as condições necessárias para que estas crianças possam ter um futuro melhor do que o abandono e a dependência da caridade, contribuindo para a erradicação da pobreza e para o crescimento de Moçambique.

Dessa forma, esperamos que o alcance total deste projeto, por meio de todas as atividades estipuladas e com base em estimativas feitas pela nossa equipe, chegue a 3.500 pessoas ao longo dos três anos nas províncias de Inhambane e Gaza. Esse número será confirmado a partir das análises feitas por meio das pesquisas inicial e final.

\section{Gestão e Coordenação do Projeto}

A implementação e organização de todas as fases do projeto serão de responsabilidade do IACD, assim como o contato com as possíveis organizações parceiras, líderes e escolas das comunidades que receberão o projeto. O UNICEF terá a função de monitorar e fiscalizar o projeto do ponto de vista financeiro e dos resultados alcançados. O organograma abaixo mostra como será feita a gestão das áreas do projeto por parte do IACD. 
Figura 3: Organograma do projeto

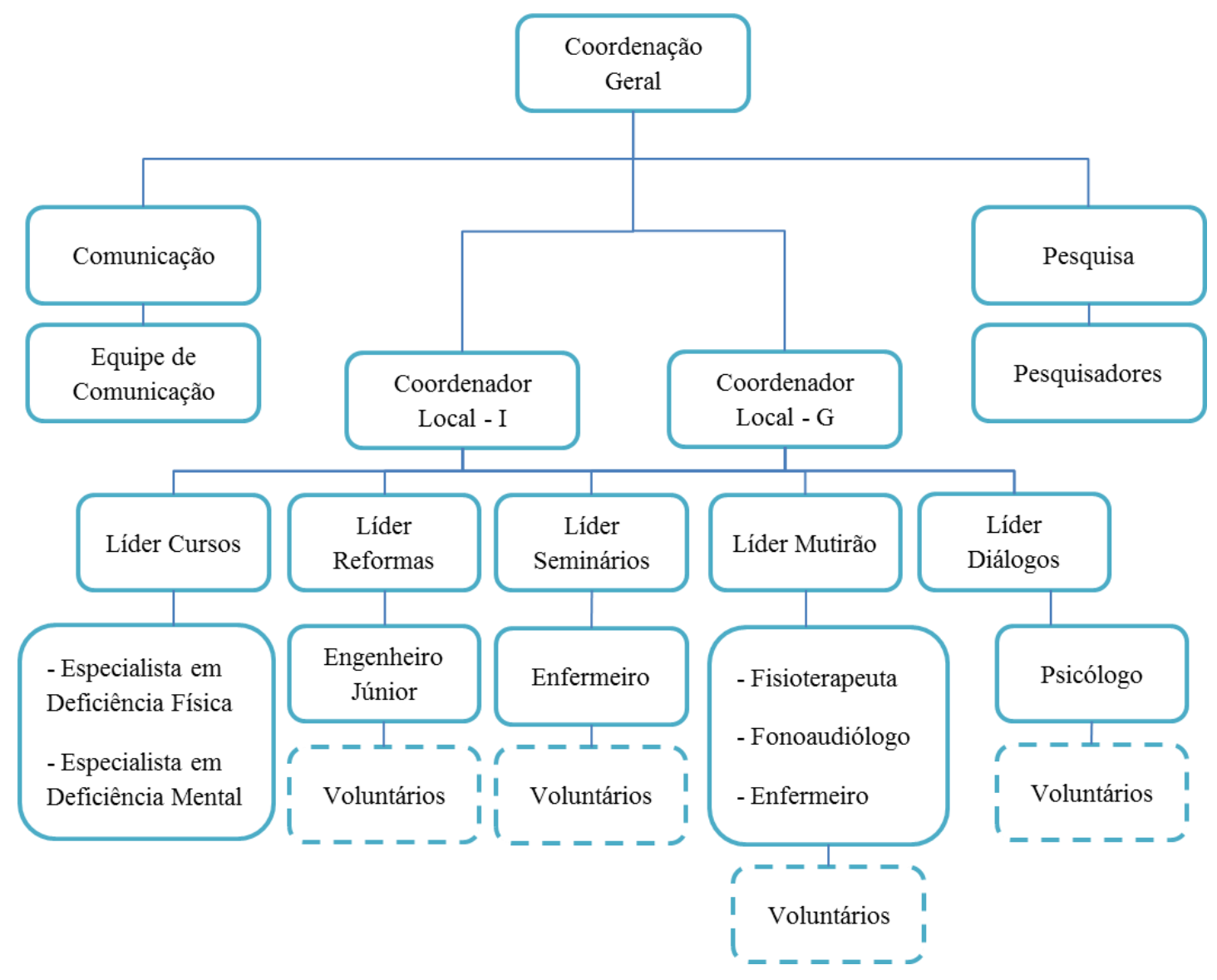

A coordenação geral do IACD será responsável por monitorar e gerir todas as grandes áreas do projeto: as pesquisas inicial e final, as duas frentes de atividades no campo e a estratégia de comunicação. Cada área, por sua vez, terá um coordenador responsável por seu pessoal e se reporta à coordenação geral para qualquer problema ou sugestão. Para evitar acúmulo de trabalho 
e consequentemente problemas de gestão, cada atividade terá um líder especializado no assunto que terá como responsabilidade gerir seus funcionários, voluntários e monitorar as atividades e se reportará diretamente ao coordenador local. A equipe de comunicação será responsável por coordenar a estratégia de comunicação e as campanhas de doação. Já a equipe de pesquisa será responsável pelas atividades de entrevistas e levantamento de dados para a criação do indicador. Os mecanismos e as formas de monitoramento serão explicados com mais detalhes no item "Monitoramento e Avaliação".

\section{Plano de trabalho:}

\section{$1^{\mathrm{a}}$ Fase: Pesquisa Inicial}

Esta fase consistirá na elaboração da primeira parte da pesquisa "A inclusão social de crianças com deficiência nas províncias de Inhambane e Gaza" e terá duração de seis meses. Essa pesquisa será feita por profissionais terceirizados, selecionados pelo IACD e coordenada por nossos funcionários contratados e com experiência no assunto. Os pesquisadores irão até os distritos das províncias de Inhambane e Gaza, em busca de comunidades que tenham casos de crianças com deficiência e averiguarão qual é a situação em que elas vivem. Entrevistarão seus familiares, vizinhos, professores e toda a comunidade em geral que convive com elas. Também avaliarão as escolas para ver se são adequadas e acessíveis para deficientes e qual tipo de material possuem para atender as necessidades especiais dessas crianças. Dadas as respostas obtidas, nossa equipe de pesquisa se reunirá para avalia-las e criar um indicador de inclusão social dessas crianças, baseado nos dados de escolaridade e na relação das crianças com a comunidade, após essa análise o resultado será publicado e disponibilizado ao público.

\section{$2^{\mathrm{a}}$ Fase: Atuação direta com as comunidades:}

Esta fase é a que concentra a maior parte dos esforços e atividades do IACD, assim como tempo do projeto, é nela que ocorrem todos os cursos, seminários, mutirões, diálogos e demais atividades. Serão criadas duas frentes de trabalho, uma para a província de Inhambane e outra para a província de Gaza, com isso seremos capazes de alcançar todos os 23 distritos ao longo dos três anos de projeto. A ordem dos distritos será feita com base nos resultados obtidos pela pesquisa inicial e terá a situação das crianças como fator de prioridade. Ou seja, os distritos que 
tiverem maior índice de exclusão das crianças com deficiência serão os primeiros a receber nossas atividades.

\section{$3^{\mathrm{a}}$ Fase: Pesquisa Final}

A pesquisa final terá os mesmos moldes e equipe da pesquisa feita ao início do projeto e terá como objetivo fazer uma nova avaliação da situação das crianças com deficiência, visando a identificação de mudanças geradas pelas atividades do projeto. A pesquisa final terá início no segundo semestre do $3^{\circ}$ ano de projeto e servirá como uma forma de concluir o projeto e o estudo feito, criando um indicador de inclusão social das crianças com deficiência e permitindo melhores análises da situação no futuro.

Monitoramento e Avaliação

\section{a) Monitoramento}

O monitoramento do projeto será feito em dois níveis. O primeiro ficará a cargo dos coordenadores locais, que serão responsáveis por liderar suas equipes e ter a certeza de que tudo está ocorrendo da melhor maneira possível. Cada líder terá a tarefa de passar relatórios mensais a respeito do andamento de suas atividades para o coordenador local e comunicá-lo imediatamente caso haja qualquer problema ou situação adversa. Haverá também reuniões mensais de entrega desses relatórios, onde os líderes poderão discutir a situação e avaliar o progresso das atividades junto com os coordenadores.

Além disso, os coordenadores serão responsáveis por manter o contato com os líderes da comunidade local e ouvir a opinião das famílias que possuem crianças com deficiência sobre o projeto, com o intuito de criar um canal de diálogo entre o IACD e a sociedade para fiscalizar o progresso do projeto aos olhos da população. Com isso teremos um mecanismo de monitoramento diretamente ligado à opinião da sociedade civil, principal beneficiário desta ação, fator que será essencial para a construção de um projeto que realmente seja eficiente em ajudar a construir uma sociedade melhor.

A partir de todas essas informações os coordenadores locais elaborarão um relatório detalhado, para ser enviado ao final das suas atividades no distrito, para avaliação da coordenação geral do IACD, que consistirá no segundo nível de monitoramento. Os diretores gerais do IACD 
farão sua própria leitura dos resultados apresentados até então e indicarão mudanças ou acertos que podem ser feitos com o intuito de melhorar as atividades. Após uma análise minuciosa e um encontro com os coordenadores locais, o IACD será responsável por mandar um novo relatório para o UNICEF, atestando os resultados obtidos e o orçamento utilizado até o momento.

A equipe de comunicação do IACD será responsável por monitorar os números relativos ao alcance da estratégia de comunicação pensada para o projeto. A partir dos números divulgados pelas mídias locais poderemos fazer uma estimativa do número de pessoas que tiveram acesso ao material de divulgação e monitorar o andamento da campanha por meio de pesquisas de opinião com amostras da sociedade.

\section{b) Relatórios}

Os relatórios utilizados para monitorar o andamento do projeto podem ser divididos em três tipos, o dos líderes, o dos coordenadores locais e de comunicação, e o do IACD. O primeiro consistirá em um resumo sobre o que ocorreu nas atividades de responsabilidade de cada líder, assim como uma prestação de contas contendo os gastos utilizados ao longo do período avaliado. Ele é elaborado pelos líderes e é entregue aos coordenadores locais. Por sua vez, os coordenadores locais se utilizam de seu conhecimento sobre a situação, o relatório anterior e as informações obtidas através das entrevistas para elaborar um relatório ainda mais detalhado que será entregue à coordenação geral do IACD.

Após uma reunião para a discussão e análise dos relatórios de cada província e da área de comunicação, a coordenação será responsável por elaborar um documento geral, que englobe todas as áreas do projeto para ser entregue ao UNICEF. Este último relatório contará com a descrição do que ocorreu durante as atividades, dados de presença e alcance das ações e uma cópia do orçamento parcial até o momento, com o objetivo de ser o mais transparente possível e criar uma relação de confiança com o órgão financiador.

\section{c) Avaliação}

Ao final do $1^{\circ}$ e do $2^{\circ}$ ano de projeto ocorrerão avaliações parciais para descobrir como está o andamento do projeto e se é necessário fazer alguma alteração para que ele seja mais 
eficiente. Essas avaliações serão feitas por meio de reuniões gerais que contarão com a presença de toda a coordenação geral, os coordenadores locais, os líderes e representantes do UNICEF. Os presentes na reunião discutirão os resultados colhidos até o momento, analisados a partir dos relatórios que foram elaborados ao longo do ano e avaliarão como se dará a continuidade do projeto, se é necessário fazer alguma alteração ou se as atividades estão saindo de acordo com planejado.

A principal avaliação dos resultados do projeto ocorrerá após o fim da segundafase de atividades, que consiste na elaboração da pesquisa final com as comunidades. A partir dessa pesquisa será possível notar se houve ou não algum progresso relacionado às ações empreendidas pelo IACD junto à população de Inhambane e Gaza. Após a análise dos resultados da pesquisa, será organizado um encontro final para discutir e avaliar o projeto, onde serão mostrados os resultados finais e depoimentos de membros das comunidades que receberam o apoio do projeto.Caso sejam observados progressos nos indicadores relacionados às atividades ao longo desses três anos, será possível dizer que obtivemos sucesso com nosso projeto. 


\section{Referências Bibliográficas}

ASSEMBLÉIA GERAL DAS NAÇÕES UNIDAS. Convenção dos Direitos das Pessoas com Deficiência.Genebra: Human Rights Office of the High Commissioner of Human Rights (OHCHR).13 dez 2006.2 Disponível em: <http://www.ohchr.org/EN/HRBodies/CRPD/Pages/ConventionRightsPersonsWithDisabilities.as px> Acesso em: 14 Nov. 2017.

CAMPOS, Arminda Eugenia Marques de; ABEGÃO, Luis Henrique; DELAMARO, Mauricio César. O Planejamento de Projetos Sociais: dicas, técnicas e metodologias. UFMG, s.d. Disponível em: <https://www.nescon.medicina.ufmg.br/biblioteca/imagem/2154.pdf>Acesso em: 14 Nov. 2017.

FÓRUM DAS ORGANIZAÇÕES DA SOCIEDADE CIVIL PARA OS DIREITOS DA CRIANÇA. Refletindo sobre as Políticas Públicas para a Área da Criança com Deficiência. Maputo: PolicyBrief, n.1, Fev. 2014.

FUNDO DAS NAÇÕES UNIDAS PARA A INFÂNCIA (UNICEF). A Pobreza na Infância em Moçambique: uma análise da situação e das tendências, s.d. Disponível em: < http://www.unicef.org/mozambique/pt/A_Pobreza_na_Infancia_em_Mocambique_Sumario.pdf> Acesso em: 5 de Jun. 2014a. 
CADERNOS DE RELAÇÕES INTERNACIONAIS, v.11, n.2, 2017.

_. Infância e Deficiência: Direitos Humanos, Equidade e Desenvolvimento Inclusivo, s.d. Disponível

em:

<http://www.mz.one.un.org/por_bid/content/download/6874/66484/file/RBB\%20UNICEF\%20M OZ12\%20Port.ppt.>Acesso em: 5 de Jun. 2014b.

_. Pobreza Infantil e Disparidades em Moçambique 2010. Maputo: Moçambique, 2011.

INSTITUTO NACIONAL DE ESTATÍSTICA (INE). Site Oficial, s.d. Maputo: República de Moçambique, s.d. Disponível em: < http://www.ine.gov.mz/pt/DataAnalysis > Acesso em: 4 Jun. 2017.

REPÚBLICA DE MOÇAMBIQUE. Plano Nacional da Área da Deficiência (PNAD II) 2012 2019. Maputo: República de Moçambique, 2012a. Disponível em: <file://C:/Users/Mariana/Downloads/Plano\%20Nacional\%20para\%20a\%20Area\%20da\%20Defi ciencia\%20-\%20PNAD\%20II\%20(2012\%20a\%202019).pdf> Acesso em: 14 Nov. 2017.

_.Plano Nacional de Ação para a Criança (PNAC II) 2013-2019. Maputo: República de Moçambique, 2012b. Disponível em: http://www.rosc.org.mz/index.php/component/docman/doc_view/152-plano-de-accao-para-acrianca-2013-2019-pnac-ii-mmas > Acesso em: 14 Nov. 2017.

_. Resolução n.20/99. 23 de Jun. 1999. Disponível em: <http://www.portaldogoverno.gov.mz/docs_gov/fold_politicas/accSocial/politica_port_deficienci a.pdf>Acesso em: 5 de Jun. 2017. 
Anexo - Quadro Lógico

\begin{tabular}{|c|c|c|c|}
\hline \multicolumn{4}{|c|}{ Objetivo Geral } \\
\hline \multicolumn{4}{|c|}{ Aumentar a inclusão social das crianças com deficiência nas províncias de Inhambane e Gaza } \\
\hline Resultados e Atividades & Indicadores & Fontes de Informação & Riscos e Pressuposições \\
\hline Resultado 1 & \multirow{4}{*}{$\begin{array}{l}\text { Grau de escolaridade, } \\
\text { taxa de evasão escolar, } \\
\text { porcentagem de } \\
\text { pessoas que veem a } \\
\text { deficiência como } \\
\text { maldição, entre outros. }\end{array}$} & \multirow{4}{*}{$\begin{array}{l}\text { Pesquisa "A inclusão } \\
\text { social de crianças com } \\
\text { deficiência nas } \\
\text { províncias de } \\
\text { Inhambane e Gaza". }\end{array}$} & Riscos \\
\hline \multirow{3}{*}{$\begin{array}{l}\text { Criação de um indicador } \\
\text { de inclusão social das } \\
\text { crianças com deficiência }\end{array}$} & & & \\
\hline & & & Pressuposição \\
\hline & & & \\
\hline Atividade 1.1 & \multirow{3}{*}{$\begin{array}{l}\text { Número de } \\
\text { participantes }\end{array}$} & \multirow{3}{*}{$\begin{array}{l}\text { Respostas dos } \\
\text { participantes }\end{array}$} & Risco \\
\hline \multirow{2}{*}{$\begin{array}{l}\text { Pesquisacom } \\
\text { acomunidade }\end{array}$} & & & $\begin{array}{l}\text { Receio da população em } \\
\text { participar das entrevistas }\end{array}$ \\
\hline & & & Pressuposição \\
\hline Resultado 2 & \multirow{4}{*}{$\begin{array}{c}\text { Taxa de evasão escolar } \\
\text { e analfabetismo. } \\
\text { Porcentagem de } \\
\text { crianças com } \\
\text { deficiência em escolas } \\
\text { regulares }\end{array}$} & \multirow{4}{*}{$\begin{array}{l}\text { Dados do INE e da } \\
\text { Associação de } \\
\text { Deficientes de } \\
\text { Moçambique }\end{array}$} & Risco \\
\hline \multirow{3}{*}{$\begin{array}{c}\text { Melhora no nível de } \\
\text { escolaridade das crianças } \\
\text { com deficiência }\end{array}$} & & & $\begin{array}{l}\text { Falta de apoio e interesse da } \\
\text { comunidade escolar }\end{array}$ \\
\hline & & & Pressuposição \\
\hline & & & $\begin{array}{l}\text { Apoio do governo no diálogo } \\
\text { com os orgãos de educação }\end{array}$ \\
\hline Atividade 2.1 & Número de professores & Listas de presença & Risco \\
\hline
\end{tabular}




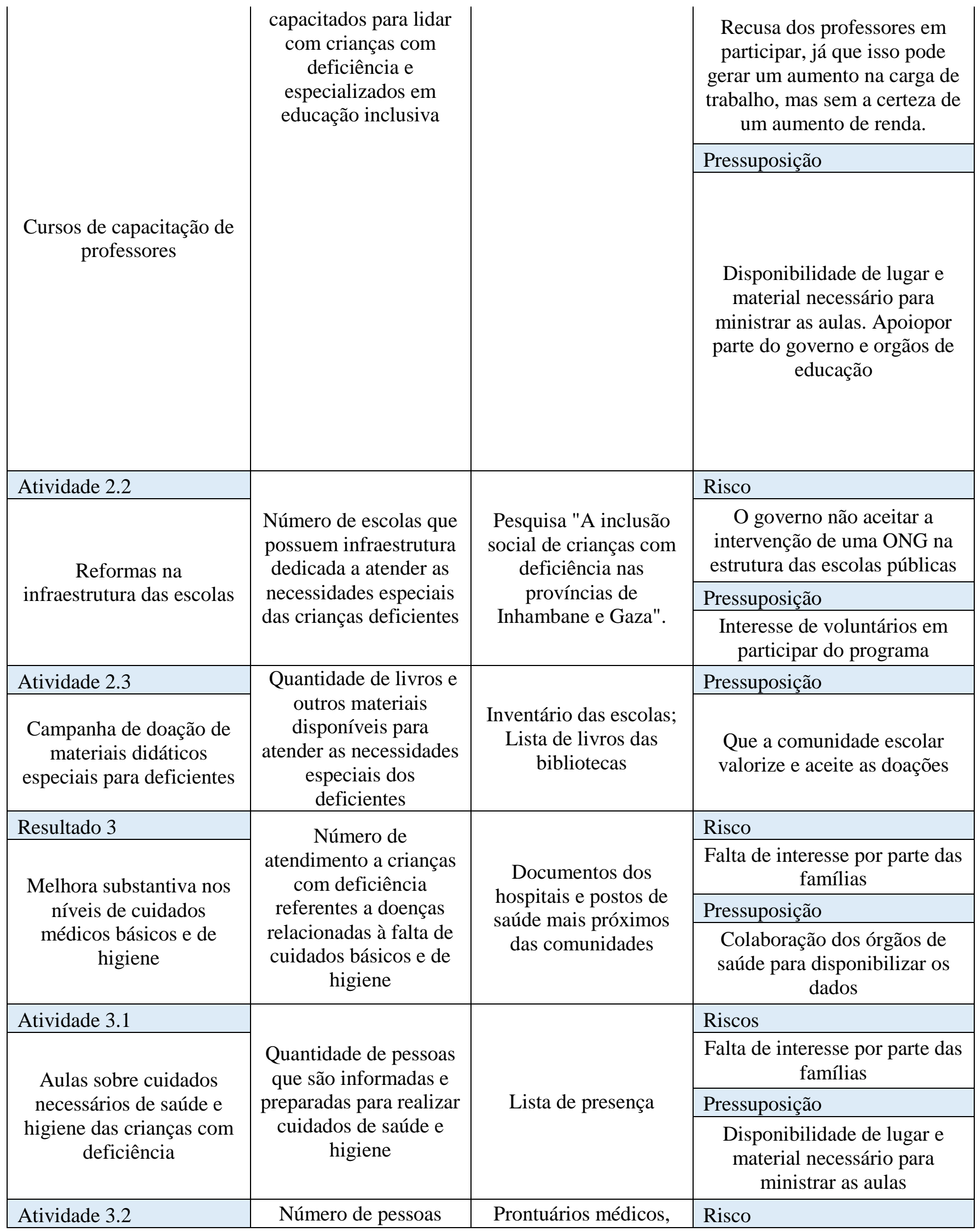




\begin{tabular}{|c|c|c|c|}
\hline \multirow[b]{3}{*}{$\begin{array}{l}\text { "Mutirões de } \\
\text { MédicosSolidários" }\end{array}$} & \multirow[t]{3}{*}{$\begin{array}{l}\text { atendidas em cada } \\
\text { mutirão }\end{array}$} & \multirow[t]{3}{*}{ listas de presença } & $\begin{array}{l}\text { Falta de adesão por parte da } \\
\text { comunidade }\end{array}$ \\
\hline & & & Pressuposição \\
\hline & & & $\begin{array}{l}\text { Disponibilidade de lugar para } \\
\text { a realização do evento }\end{array}$ \\
\hline Resultado 4 & \multirow[b]{3}{*}{$\begin{array}{c}\text { Número de pessoas que } \\
\text { acredita que a } \\
\text { deficiência é fruto de } \\
\text { uma maldição ou } \\
\text { feitiço }\end{array}$} & \multirow[b]{3}{*}{$\begin{array}{l}\text { Dados da pesquisa "A } \\
\text { inclusão social de } \\
\text { crianças com } \\
\text { deficiência nas } \\
\text { províncias de } \\
\text { Inhambane e Gaza" }\end{array}$} & Risco \\
\hline \multirow[b]{2}{*}{$\begin{array}{l}\text { Diminuição do } \\
\text { preconceito e estigma em } \\
\text { relação à deficiência }\end{array}$} & & & $\begin{array}{l}\text { Falta de apoio dos líderes } \\
\text { religiosos e da comunidade }\end{array}$ \\
\hline & & & Pressuposição \\
\hline Atividade 4.1 & \multirow{4}{*}{$\begin{array}{l}\text { Número de } \\
\text { participantes nos } \\
\text { encontros }\end{array}$} & \multirow{4}{*}{ Lista de presença } & Risco \\
\hline \multirow{3}{*}{$\begin{array}{l}\text { Realização dos "Diálogos } \\
\text { sobre a deficiência" }\end{array}$} & & & $\begin{array}{c}\text { Falta de interesse da } \\
\text { comunidade; Receio em deixar } \\
\text { de acreditar em suas crenças e } \\
\text { religião }\end{array}$ \\
\hline & & & Pressuposição \\
\hline & & & $\begin{array}{c}\text { Existência de lugares aptos } \\
\text { para a realização dos } \\
\text { encontros }\end{array}$ \\
\hline Atividade 4.2 & \multirow{4}{*}{$\begin{array}{c}\text { Número de anúncios e } \\
\text { propagandas } \\
\text { defendendo a inclusão } \\
\text { social nas mídias locais }\end{array}$} & \multirow{4}{*}{$\begin{array}{l}\text { Documentos } \\
\text { disponibilizados pelos } \\
\text { meios de comunicação }\end{array}$} & Risco \\
\hline \multirow{3}{*}{$\begin{array}{l}\text { Estratégia de } \\
\text { comunicação englobando } \\
\text { as principais formas de } \\
\text { mídia }\end{array}$} & & & $\begin{array}{l}\text { Rejeição da população aos } \\
\text { anúncios veiculados }\end{array}$ \\
\hline & & & Pressuposição \\
\hline & & & $\begin{array}{l}\text { Apoio por parte dos meios de } \\
\text { comunicação }\end{array}$ \\
\hline Atividade 4.3 & Número de & Número de & Pressuposição \\
\hline
\end{tabular}


CADERNOS DE RELAÇÕES INTERNACIONAIS, v.11, n.2, 2017.

\begin{tabular}{|c|c|c|c|}
\hline $\begin{array}{l}\text { Realização do festival } \\
\text { "Arte para todos" }\end{array}$ & espectadores & ingressosdistribuídos & $\begin{array}{l}\text { Apoio e interesse das } \\
\text { comunidades na realização do } \\
\text { evento }\end{array}$ \\
\hline
\end{tabular}

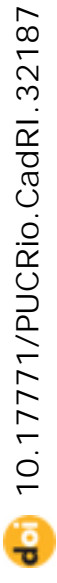

